\title{
PVP2014-28006
}

\section{MOISTURE ADSORPTION CONSIDERATIONS FOR PACKAGING PLUTONIUM OXIDE}

\author{
James E. Laurinat \\ Savannah River National Laboratory \\ Savannah River Site, Aiken, SC 29808 \\ Email: james.laurinat@srnl.doe.gov
}

\author{
Steve J. Hensel \\ Savannah River Nuclear Solutions \\ Savannah River Site, Aiken, SC 29808 \\ Email: steve.hensel@srnl.doe.gov
}

\begin{abstract}
Compliance with DOE-STD-3013, Stabilization, Packaging, and Storage of Plutonium-Bearing Materials, requires plutonium oxide to be stabilized at high temperatures such that the material is non-reactive and has less than $0.5 \% \mathrm{wt}$. moisture adsorption [1]. Since plutonium oxide is known to readily adsorb moisture, compliance with the standard requires a sample of oxide material to be measured for moisture adsorption. The measurement is typically done using Thermo Gravimetric analysis (TGA). The sample must be representative of the actual oxide material in order for the TGA measurement to be valid. Obtaining a representative sample from an oxide powder container may be done using a core sampler or a grab sample method that accounts for potential spatial distribution of the oxides. A further complication with moisture sampling is that the plutonium oxide typically continues to adsorb moisture from the glove box ambient for many hours or even days until equilibrium is reached. In typical oxide material handling operations, the material, both product and sample, is canned and bagged out prior to equilibrium conditions are achieved. In fact, given the strict moisture requirement for DOE-STD-3013 compliance, it is highly undesirable to allow for equilibrium moisture adsorption to be achieved. Given the dynamic nature of moisture adsorption, a technical basis for obtaining a representative sample is important for DOE-STD-3013 compliance. The technical basis not only includes how the sample is obtained, but more importantly, must account for all handling once the sample is physically separated from the product. This paper provides an analytical basis for moisture adsorption to define handling controls that assures a representative oxide sample is obtained.
\end{abstract}

\section{INTRODUCTION}

The HB-Line facility at the United States Department of Energy (DOE) Savannah River Site (SRS) is preparing to begin plutonium oxide processing activities in order to provide alternate feed for the Mixed Oxide Fuel Fabrication Facility (MFFF) which is currently under construction at the SRS. Plutonium oxide feed for the MFFF will be compliant with DOE-STD-3013. This standard establishes both packaging and stabilization processing requirements for plutonium oxide. The packaging requirements include double nested welded stainless steel vessels. The processing requirements include adsorbed moisture to be no more than $0.5 \% \mathrm{wt}$. in order to protect against excessive pressurization and corrosion of the welded containers. Compliance with the $0.5 \%$ wt. moisture limit is demonstrated by sampling the final oxide product and measuring the adsorbed moisture. This necessitates a representative sample be obtained. Given the dynamic nature of moisture adsorption onto plutonium oxide and the HB-line processing glove box is not a dry air system, well defined plutonium oxide handling and controls are needed to ensure a representative sample is obtained. It should be noted that the product container depicted in this work will be used for an interim packaging until a 3013 welding capability is established. Nevertheless, the interim packaging will satisfy the moisture requirements per DOE-STD-3013.

A core sampler will be used to pull product samples after the plutonium oxide is stabilized and dumped from the furnace into the product can. These samples include that for moisture measurement, impurity measurements, and plutonium oxide physical property measurements such as density, specific surface area and particle size. The product can contains approximately $1 \mathrm{~kg}$ of oxide. The core sampler is pushed through the can of oxide until the sampler reaches the bottom. Next, a screw mechanism closes the small chambers which extract oxide at discrete heights. The core sampler is removed from the can and it now has extracted oxide which will be representative of the entire can. This extracted amount is on the order of $25 \mathrm{~g}$. The oxide in the core sampler will be transferred into a small slip lid can where it will be mixed by lightly shaking the slip lid can with its lid in place. Smaller sub

The United States Government retains, and by accepting the article for publication, the publisher acknowledges that the Unites States Government retains, a non-exclusive, paid-up, irrevocable worldwide license to publish or reproduce the published form of this work, or allow others to do so, for United States Government purposes. This work was prepared under Federal Contract DE-AC09-08SR22470. 
samples of 4 -6 g of oxide will be transferred into separate BVials. The exact sample mass, number of samples, and process for obtaining the samples is prescribed per a Use Every Time (UET) procedure. After an appropriate amount of oxide is placed into the B-Vial, the B-Vial cap is placed on the vial and turned one revolution. Transfer of oxide from the slip lid container to additional B-Vials occurs until all samples have been taken or oxide in the slip lid container is consumed. An important aspect to the sampling is for the moisture sample to be handled first as it will be shown that excessive sample handling will result in a conservatively high moisture measurement. The oxide product is sampled using additional core samples as needed and additional B-Vials are similarly prepared.

\section{NOMENCLATURE}

$\mathrm{R}_{\mathrm{p} 1}$ moisture adsorption rate on product openly exposed to glove box

$\mathrm{R}_{\mathrm{p} 2} \quad$ moisture adsorption rate on product with lid on

$\mathrm{R}_{\mathrm{s} 1}$ moisture adsorption rate on sample openly exposed to glove box

$\mathrm{R}_{\mathrm{s} 2}$ moisture adsorption rate on sample in B-vial without lid

$\mathrm{R}_{\mathrm{s} 3}$ moisture adsorption rate on sample in closed B-Vial (one turn)

$\mathrm{T}_{\mathrm{p} 1} \quad$ time the product is openly exposed such as during subsequent core sampling (no lid on)

$\mathrm{T}_{\mathrm{p} 2} \quad$ time the product container is closed prior to sealing the outer plastic bag

$\mathrm{T}_{\mathrm{s} 1}$ time the sample is openly exposed through core sample handling and open slip lid

$\mathrm{T}_{\mathrm{s} 2} \quad$ time the sample is exposed in B-vial without lid

$\mathrm{T}_{\mathrm{s} 3}$ time the sample is in the closed (one turn) B-Vial

\section{SAMPLING ANALYSIS}

The sample of oxide becomes distinct from the oxide product once the core sample is extracted. Care must be taken to ensure that the oxide product does not adsorb moisture beyond that which is adsorbed by the sample, otherwise the sample will falsely under predict the average moisture of the oxide in the product. Similarly, excessive handling of the oxide sample may result in elevated moisture adsorption and falsely indicate noncompliance with the DOE-STD-3013. Moisture adsorption calculations have been performed to estimate the quantity of moisture adsorbed as a function of time for both samples and product. These calculations will be used to demonstrate that the sample oxide has as much or more adsorbed moisture than the product oxide, and therefore is a representative sample for moisture measurement. The moisture adsorption evaluation commences once the sample is extracted using the core sampler and ends when the product can is bagged out of the glove box and sealed in a plastic bag thus preventing additional moisture adsorption. The sample vials are tightly closed at this time.

The criteria for maintaining a representative sample requires the moisture adsorption after pulling the sample to be greater for the sample taken than for the product. Using moisture adsorption rates and exposure time the criterion can simply be expressed as:

$$
\mathrm{T}_{\mathrm{s} 1} * \mathrm{R}_{\mathrm{s} 1}+\mathrm{T}_{\mathrm{s} 2} * \mathrm{R}_{\mathrm{s} 2}+\mathrm{T}_{\mathrm{s} 3} * \mathrm{R}_{\mathrm{s} 3}>\mathrm{T}_{\mathrm{p} 1} * \mathrm{R}_{\mathrm{p} 1}+\mathrm{T}_{\mathrm{p} 2} * \mathrm{R}_{\mathrm{p} 2}
$$

The moisture adsorption rates for $50 \%$ and $70 \%$ relative humidity are provided in Tables 1 and 2. These rates represent the average moisture in the container or sample vial. Note that this moisture is considered loosely bound where total moisture includes a small added amount of strongly bound (chemisorbed) moisture. They are based upon work done by Laurinat et. al [2], and the methodology used to calculate moisture adsorption rates has been benchmarked. In this work a computational model was developed to determine transient moisture adsorption within the oxide of both the sample vial and product container. Figures 1 and 2 provide a contour plot of moisture adsorption for the sample vial and product container (the plots are in the $\mathrm{r}-\mathrm{z}$ plane as the analysis is axisymmetric). These figures show that the moisture adsorption is much higher at the top oxide layer in each container. At equilibrium the concentration would be uniform, except for variation due to local temperature in the oxide from radioactive decay self heating. Note that a linear approximation for the moisture adsorption rate is appropriate for the time frame under consideration, so the rates may be applied as constants. Also, note that the sum of $\mathrm{T}_{\mathrm{p} 1}$ and $\mathrm{T}_{\mathrm{p} 2}$ is the total time allowed after pulling the core sample (for the moisture sample) until the outer bag for the product can is sealed after it is removed from the glove box.

Table 1: Moisture Adsorption Rates, $50 \%$ Relative Humidity

\begin{tabular}{|l|c|}
\hline Configuration and Moisture Adsorption Condition & Moisture Adsorption Rate (Percent per minute) \\
\hline $\mathrm{Pu}$ oxide fully exposed & $0.0253 \%$ per minute $\left(\mathrm{R}_{\mathrm{s} 1}\right)$ \\
\hline $\mathrm{Pu}$ oxide in open B-Vial & $0.00307 \%$ per minute $\left(\mathrm{R}_{\mathrm{s} 2}\right)$ \\
\hline $\mathrm{Pu}$ oxide in closed B-Vial (one turn) & $0.00000475 \%$ per minute $\left(\mathrm{R}_{\mathrm{s} 3}\right)$ \\
\hline $\mathrm{Pu}$ oxide in open product container ${ }^{* * *}$ & $0.00091 \%$ per minute $\left(\mathrm{R}_{\mathrm{p} 1}\right)$ \\
\hline $\mathrm{Pu}$ oxide in closed product container & ${ }^{* * * *}$ \\
\hline
\end{tabular}


SRNL-STI-2014-00048

Table 2: Moisture Adsorption Rates, $70 \%$ Relative Humidity

\begin{tabular}{|l|c|}
\hline Configuration and Moisture Adsorption Condition & Moisture Adsorption Rate (Percent per minute) \\
\hline Pu oxide fully exposed & $0.0280 \%$ per minute $\left(\mathrm{R}_{\mathrm{s} 1}\right)$ \\
\hline Pu oxide in open B-Vial & $0.0046 \%$ per minute $\left(\mathrm{R}_{\mathrm{s} 2}\right)$ \\
\hline $\mathrm{Pu}$ oxide in closed B-Vial (one turn) & $0.0000068 \%$ per minute $\left(\mathrm{R}_{\mathrm{s} 3}\right)$ \\
\hline Pu oxide in open product container & $0.00137 \%$ per minute $\left(\mathrm{R}_{\mathrm{p} 1}\right)$ \\
\hline Pu oxide in closed product container & ${ }^{* * * *}$ \\
\hline
\end{tabular}

* The fully exposed sample adsorption rate is based on the rate during the first 15 minutes of oxide exposed to humid air at the oxide surface

** The open B-Vial container adsorption rate is based on the rate during the first 15 minutes of moisture diffusion from the top of the B-Vial, which is conservative

*** The open product container adsorption rate is based on the rate during the first 20 minutes with the diffusion of moisture applied at the best estimate distance below the can top due to mixing considerations

**** The closed product container adsorption rate is based on the rate during the first 60 minutes with diffusion of moisture applied at the top of the can which effectively assumes the filter has limitless moisture permeability

The acceptance criterion for maintaining a representative sample is evaluated based on observations made during sampling procedure execution the mock-up of the HB-Line mechanical line. Three different operating scenarios; mock-up, accelerated, off-normal were evaluated as shown in Table 3. The values for $T_{s 1}$ (time sampled oxide is openly exposed) includes core sampling, transfer to slip lid can, and extracting an exact amount into a sample vial. Likewise, the values for $\mathrm{T}_{\mathrm{p} 1}$ (time product oxide is openly exposed) is conservatively high since the lid shall be in place on the product can other than when core sampling is in process. This was not the case during the mock-up runs as the lid remained off the product container. Lastly, the time allowed after sampling for moisture to bag out the product container, place it into the outer can, and seal the outer can in a plastic bag is varied depending on the case under consideration.

Information from a mock-up exercise is used as the first operational case. An accelerated case is provided since moisture adsorption on the sample would be greatly reduced if operations were performed significantly faster than during the mock-up. For conservatism, the time until the product is bagged out remains at 120 minutes as in the mock-up. This shows that even with faster operations for sampling, and therefore less moisture adsorbed by the sample, the sample is representative. An additional off-normal case using more realistic processing times than occurred during the mock-up is included with an upper bound for the time until the product can is bagged out of 360 minutes. For all three base operational cases the moisture adsorbed by the sample is at least 1.5 times that adsorbed on the product for both $50 \%$ and $70 \%$ relative humidity (see Tables 3 and 4). Therefore, the sample bounds the product in terms of a moisture measurement with some margin. Interestingly, the effect of increasing relative humidity appears to result in decreasing margin as can be seen in comparing the last column in Tables 3 and 4 . Operating at 70\% relative humidity is not anticipated as this is an upper bound used for this evaluation. Operating at lower relative humidity, such as during winter months, should result in more margin.

Additional cases have been evaluated to provide a sense of margin with respect to handling time of the product. For example, the bag out time is increased to 240 and 300 minutes and margin remains even with the accelerated handling scenario, where moisture adsorption on the sample is minimal. Not until the product bag out takes over 5 hours does the average moisture of the product equal that of the sample. Therefore, a reasonable restriction on operations is an interruption of 3 hours (180 minutes). Should an interruption of 3 hours occur after the moisture sample is pulled, a substitute sample should be taken.

The results in Tables 3 and 4 also indicate the sensitivity of excessive handling of the sample. Sample handling $\left(\mathrm{T}_{\mathrm{s} 1}+\mathrm{T}_{\mathrm{s} 2}\right)$ greater than 20 minutes will likely result in a moisture measurement approaching $0.40 \%$ which is the maximum threshold for acceptance (assume approximately $0.1 \%$ for tightly bound moisture to be added to the loosely bound moisture). It is also worth noting that Figure 1 indicates the importance of using the entire sample for moisture analysis as opposed to taking a grab sample from the top of the sample vial. 
Table 3: Time allowed to Bag Outer Product can and Loosely Bound Moisture, $\mathbf{5 0} \%$ Relative Humidity

\begin{tabular}{|l|c|c|c|c|c|c|}
\hline $\begin{array}{l}\text { Operational } \\
\text { Case }\end{array}$ & $\begin{array}{l}\mathrm{T}_{\mathrm{s} 1} \\
\min \end{array}$ & $\begin{array}{l}\mathrm{T}_{\mathrm{s} 2} \\
\mathrm{~min}\end{array}$ & $\begin{array}{l}\mathrm{T}_{\mathrm{p} 1} \\
\mathrm{~min}\end{array}$ & $\begin{array}{l}\mathrm{T}_{\mathrm{p} 2} \\
\mathrm{~min}\end{array}$ & $\begin{array}{l}\text { Sample } \\
\text { Moisture }\end{array}$ & $\begin{array}{l}\text { Moisture } \\
\text { sample/ } \\
\text { Moisture } \\
\text { product }\end{array}$ \\
\hline $\begin{array}{l}\text { Mock-up } \\
\text { (base) }\end{array}$ & $>8$ & $>8$ & $<20$ & $<120$ & $0.23 \%$ & 5.9 \\
\hline Mock-up & $>8$ & $>8$ & $<20$ & $<240$ & $0.23 \%$ & 3.9 \\
\hline Mock-up & $>8$ & $>8$ & $<20$ & $<300$ & $0.23 \%$ & 3.3 \\
\hline $\begin{array}{l}\text { Accelerated } \\
\text { (base) }\end{array}$ & $>3$ & $>3$ & $<13$ & $<120$ & $0.09 \%$ & 2.6 \\
\hline Accelerated & $>3$ & $>3$ & $<13$ & $<240$ & $0.09 \%$ & 1.6 \\
\hline Accelerated & $>3$ & $>3$ & $<13$ & $<300$ & $0.09 \%$ & 1.4 \\
\hline Accelerated & $>3$ & $>3$ & $<13$ & $<440$ & $0.09 \%$ & 1.0 \\
\hline $\begin{array}{l}\text { Off-normal } \\
\text { (base) }\end{array}$ & $>5$ & $>7$ & $<15$ & $<360$ & $0.15 \%$ & 2.0 \\
\hline
\end{tabular}

Table 4: Time allowed to Bag Outer Product can and Loosely Bound Moisture, 70\% Relative Humidity

\begin{tabular}{|l|c|c|c|c|c|c|}
\hline $\begin{array}{l}\text { Operational } \\
\text { Case }\end{array}$ & $\begin{array}{l}\mathrm{T}_{\mathrm{s} 1} \\
\mathrm{~min}\end{array}$ & $\begin{array}{l}\mathrm{T}_{\mathrm{s} 2} \\
\mathrm{~min}\end{array}$ & $\begin{array}{l}\mathrm{T}_{\mathrm{p} 1} \\
\mathrm{~min}\end{array}$ & $\begin{array}{l}\mathrm{T}_{\mathrm{p} 2} \\
\mathrm{~min}\end{array}$ & $\begin{array}{l}\text { Sample } \\
\text { Moisture }\end{array}$ & $\begin{array}{l}\text { Moisture } \\
\text { sample/ } \\
\text { Moisture } \\
\text { product }\end{array}$ \\
\hline $\begin{array}{l}\text { Mock-up } \\
\text { (base) }\end{array}$ & $>8$ & $>8$ & $<20$ & $<120$ & $0.26 \%$ & 4.5 \\
\hline Mock-up & $>8$ & $>8$ & $<20$ & $<240$ & $0.26 \%$ & 3.0 \\
\hline Mock-up & $>8$ & $>8$ & $<20$ & $<300$ & $0.26 \%$ & 2.6 \\
\hline $\begin{array}{l}\text { Accelerated } \\
\text { (base) }\end{array}$ & $>3$ & $>3$ & $<13$ & $<120$ & $0.10 \%$ & 2.1 \\
\hline Accelerated & $>3$ & $>3$ & $<13$ & $<240$ & $0.10 \%$ & 1.3 \\
\hline Accelerated & $>3$ & $>3$ & $<13$ & $<300$ & $0.10 \%$ & 1.1 \\
\hline Accelerated & $>3$ & $>3$ & $<13$ & $<320$ & $0.10 \%$ & 1.0 \\
\hline $\begin{array}{l}\text { Off-normal } \\
\text { (base) }\end{array}$ & $>5$ & $>7$ & $<15$ & $<360$ & $0.17 \%$ & 1.6 \\
\hline
\end{tabular}

\section{SUMMARY AND CONCLUSIONS}

In conclusion, a linear analysis of moisture adsorption for both oxide samples and product have been evaluated using moisture adsorption rates developed from a computational model for both the sample vial and product container. The sampling procedure was executed in a mock up facility in order to obtain process times. Various operational scenarios, based on the mock up, have been evaluated in order to determine how much time can lapse after moisture samples are pulled such that the moisture sample remains a representative sample of the product. For this application a representative sample is one whose moisture content is equal or greater than the actual product. The time lapse identified is an interruption to operations of no more than 3 hours. Should operations become interrupted for 3 hours after the moisture sample is taken, a new moisture sample should be taken once processing operations resume. Lastly, the analysis provides an indication that moisture samples should be within the $0.5 \%$ wt. moisture requirement of DOE-STD-3013 provided the entire contents of the sample vial are analyzed.

\section{REFERENCE}

1. DOE-STD-3013-2012, "Stabilization, Packaging, and Storage of Plutonium-Bearing Materials".

2. Laurinat, J. E., Kesterson, M. R., and Hensel, S. J., "Analysis of the Rate of Adsorption of Moisture onto Plutonium Oxide Powders” ASME PVP2014-28073. 